\title{
Associated Factors with Pre-eclampsia Among Pregnant Women Attending Antenatal Care in SOS Hospital Mogadishu, Somalia: A Hospital-based Study
}

\author{
Omar Dahir ${ }^{1, ~ *, ~ S a m i o ~ M o h a m u d ~}{ }^{1}$, Ahmed Abdinoor ${ }^{1}$, Gallad Dahir $^{2}$, Hoda Abdinur ${ }^{2}$ \\ ${ }^{1}$ Department of Public Health, College of Medicine and Health Science, University of Somalia, Mogadishu, Somalia \\ ${ }^{2}$ Department of Public Health, College of Medicine and Health Science, Jamhuriya University of Science and Technology, Mogadishu, \\ Somalia
}

Email address:

omarshaani@gmail.com (O. Dahir), samiosom65@gmail.com (S. Mohamud), ahmedshmahbub@gmail.com (A. Abdinoor), galladph@gmail.com (G. Dahir), hodaabdi1005@gmail.com (H. Abdinur)

${ }^{*}$ Corresponding author

\section{To cite this article:}

Omar Dahir, Samio Mohamud, Ahmed Abdinoor, Gallad Dahir, Hoda Abdinur. Associated Factors with Pre-eclampsia Among Pregnant Women Attending Antenatal Care in SOS Hospital Mogadishu, Somalia: A Hospital-based Study. Central African Journal of Public Health. Vol. 6, No. 6, 2020, pp. 326-331. doi: 10.11648/j.cajph.20200606.12

Received: October 14, 2020; Accepted: October 28, 2020; Published: November 4, 2020

\begin{abstract}
Background and objective: Preeclampsia is a condition that affects some pregnant women during the second half of their pregnancy. It is estimated that $3-5 \%$ of all pregnancies is affected by preeclampsia and it has become the leading cause of maternal and fetal morbidity and mortality across the world. The objective of this study was to determine risk factors associated with Pre-eclampsia among pregnant women attending antenatal care in SOS hospital. Methods: A cross-sectional hospital-based study was conducted among 80 pregnant women attending antenatal care in SOS hospital. Face to face interview questionnaire was performed from April to June 2020. SPSS version 23, was used for the data analysis. Sociodemographic of respondent, previous history of chronic disease obstetric characteristics were described using the statistics of frequency and Percentage distributions. Results: of the 80 of the diagnosed with preeclampsia, majority of the them were above the age of 30 this represented $33.8 \%$ depict that there is a high rate of preeclampsia cases in extreme ages. Divorced women had higher percentage of $61.3 \%$ compared to widowed and married women with $33.8 \%$ and 5 percent respectively. High blood pressure was high among the women tested with $77.5 \%$ of them had the history of hypertension. Majority of the women interviewed $76.3 \%$ had no family history of preeclampsia. Conclusion: the prevalence of preeclampsia variation was related by maternal age, maternal education, unemployed women, family problem, and previous history of hypertension and used women more salts during pregnancy. Among the pregnant women, those that were in the first trimester were almost the same as those that were at their third trimester with $42.5 \%$ and $38.8 \%$ respectively. Only $42.5 \%$ of the gestational age of pregnancy were at their first trimester. Regular training of health workers on preeclampsia causes, effects and how to prevent it from becoming a long lasting issue among pregnant women need to be addressed and for further studies are recommended.
\end{abstract}

Keywords: Preeclampsia, Pregnant Women, Antenatal Care

\section{Introduction}

Preeclampsia is a condition that affects some pregnant women during the second half of their pregnancy. It is estimated that $3-5 \%$ of all pregnancies is affected by preeclampsia and it has become the leading cause of maternal and fetal morbidity and mortality across the world $[1,2]$. It is characterized by high blood pressure, a risk factor that make them vulnerable to this complication because of economic and nutritional transition, and the consequent changing lifestyle and demographics [3]. Goal 3 of the sustainable development goals requires to all countries to improve maternal health by reducing maternal mortality and to achieve access reproductive health care services $[4,5]$. One of the common causes of maternal mortality is preeclampsia, which is mainly related to a blood pressure and proteinuria $[6$, 
7]. Preeclampsia mostly begins after 20 weeks of pregnancy in women whose blood pressure had been normal [8]. Preeclampsia is one of the leading causes of maternal mortality and morbidity, complicating an estimated $2-8 \%$ of pregnancies worldwide and up to $10 \%$ in developing countries [9]. In Ethiopia, the prevalence of preeclampsia is estimated to be $13.0 \% \%$. It is one of the top five leading causes of maternal and neonatal deaths $[7,10]$.

Somalia war broke up early 1991 leading to the shattering of all governmental institutions mainly the health sector which blocked the progress towards improving the health sector in Somalia [11]. People, mainly women and children were forced to be displaced leading to lack of access to an appropriate health care facility. Since then, there has been a surge in mortality rates above the commonly used thresholds for the crisis reflecting a critical health situation [12]. The causes of maternal morbidity and mortality are multifactorial. An in-deeply analysis on the trends of maternal health in Somalia related to demographic, social behavioral, nutritional, and health services related factors are associated with poor maternal health outcomes [13].

According to WHO, significant number of maternal deaths (16\%) worldwide were caused by preeclampsia However, preeclampsia was much higher in the least developed countries (12 per cent) and was particularly low in Europe (3 per cent) $[14,7]$.

Currently in Somalia, the magnitude of the death caused by preeclampsia rates is high making it the second leading cause of pregnancy-related intensive care unit admissions after obstetric hemorrhage. One quarter of stillbirth and neonatal deaths in Somalia are associated with preeclampsia/eclampsia. Infant's mortality are associated with preeclampsia in three time higher in the country, large due to the lack of neonatal intensive care facilities $[10,11]$. This is characterized by a specific low-income of the country situation with a mix of newly urbanized and nomadic culture combined with a frail health care infrastructure set in a postconflict era. Generally, in Somalia there are limited studies on the prevalence and associated factors of pre-eclampsia. Availing up to date information on the magnitude and contributing factors of pre-eclampsia is essential for its early identification and management. Therefore, this studies was based on primary data will shade light on the increasing maternal and fetal mortality caused by untreated preeclampsia and the study will also explore the associated factors and prevalence contributing to preeclampsia among women.

\section{Materials and Methods}

\subsection{Study Setting}

This a hospital based cross sectional study design that was conducted in SOS hospital to determine the risk factors associated with Pre-eclampsia among pregnant women attending antenatal care in SOS hospital. Face-to-face interview questionnaire was performed during the study.

\subsection{Study Site}

This study was conducted in SOS hospital, Mogadishu, Somalia. SOS hospital is one of biggest maternal and child hospital and admits many mother and child who suffer different disease. SOS hospital was established in 1989 in Mogadishu by SOS children's Villages, it consists of 26 sick beds, 19 treatment rooms, there are four gynecologists, 18 midwifes and several nurses provide 100 patients with medical treatment each day. An average of 15 babies are born at the clinic each day. SOS hospital has a capacity of 30,000 persons per year according to data that received for this report.

\subsection{Inclusion/Exclusion Criteria}

The study population are mothers at SOS hospital who were suffering from preeclampsia and greed to participate in this study report by signing an informed consent that was included into the study. Mother who were seriously sick and unable to be interviewed during the study period and mother who felt uncomfortable to answer the questions and refused to participate were excluded.

\subsection{Sample Size}

Non probability (Available) samples was used and collected from 15April to 15 June 2020 on (Saturday, Monday, Wednesday and Thursday) in each week. The sample size had been total number of pregnant mother with preeclampsia that were available during data collection from 15April to 15 June 2020.

$$
\begin{aligned}
& \text { Mother socio-demographic factor } \\
& \text { - age } \\
& \text { - marital status } \\
& \text { - income } \\
& \text { - education }
\end{aligned}
$$

\section{History of chronic disease}

- history of diabetics

- history of hypertension

- history of kidney disease

\section{Obstetric characteristics}

- have proteinuria

- attending ANC

- history of family problem

- gestational age

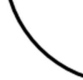

Figure 1. Conceptual framework of preeclampsia on pregnant women.

\subsection{Data Collection Methods}

Two public health officers filled out the questionaires from particpants. Particpants were also given- information about the research objectives, as well as research question that the study intended to answer prior to the interviews. The questioanire was first prepared in English and then translated 
to Somali language which was the native language for mothers and was transalated back to english in order to check and maintain its consistency. Data were collected by face to face interview technique using pretested questionaire. Content validity of questionnaire was validated by 3 experts in the field of reproductive health according to expert opinion was performed before actual data collection.

\subsection{Statistical Analysis}

The Statistical Package for the Social Sciences (SPSS), version 23, was used for the data analysis. Frequency tables and cross tabulations showing frequency counts and percentage distributions were used to present the analyzed quantitative data. The analysis was composed 3 variables including, socio-demographic characteristics, previous history of chronic disease and the last one is obstetric and clinical characteristics.

\subsection{Ethical Consideration}

Ethics approval was obtained from the University of Somalia, college of Medicine and Health science. A formal permission letter was taken from the hospital management before the beginning data collection. The respondents were also given information about the research objectives, as well as research question that the study intended to answer prior to the interviews and a written informed consent was obtained from all respondents before interviewed and ask permission to complete questionnaire.

\section{Results}

\subsection{Socio Demographic Characteristics}

A total of eighty pregnant women were enrolled in the study. The majority of the participants who were diagnosed with preeclampsia were above the age of 30 this represented $33.8 \%$ followed by age bracket of 25-30 representing 30\%. At the age bracket of 20-25 represented $25.0 \%$ Age bracket of $15-20$ represented only $11 \%$. The data depict that there is a high rate of preeclampsia cases in extreme ages. Divorced women had higher percentage of $61.3 \%$ compared to widowed and married women with $33.8 \%$ and 5.0 percent respectively. Majority of the respondent $(43.8 \%)$ were able to read and write while those who completed school took the second chance (35\%). 17.5\% were not able to read or write only $3.8 \%$ made to university. in terms of employment, $76.3 \%$ of the respondents were unemployed and only $23.8 \%$ were employed. A significant number of the respondent's monthly income $63.8 \%$ was between $200 \$$ to $300 \$ 26 \%$ were earning between $300 \$$ to $400 \$$ and $8.8 \%$ of them had a monthly income of between $400 \$-500 \$$.

Table 1. Socio demographic characteristics.

\begin{tabular}{lll}
\hline Variables & $(\mathbf{n = 8 0})$ & $\mathbf{\%}$ \\
\hline Mother Age & & \\
15-20 year & 9 & 11.3 \\
20-25 year & 20 & 25.0 \\
25-30 year & 24 & 30.0 \\
\hline
\end{tabular}

\begin{tabular}{lll}
\hline Variables & $\mathbf{( n = 8 0 )}$ & $\mathbf{\%}$ \\
\hline above 30 year & 27 & 33.8 \\
Marital status & & \\
Married & 27 & 33.8 \\
Divorce & 49 & 61.3 \\
Window & 4 & 5.0 \\
Educational attainment & & \\
Unable to read and write & 14 & 17.5 \\
able to read and write & 35 & 43.8 \\
School & 28 & 35.0 \\
University & 3 & 3.8 \\
Occupation & & \\
Employee & 19 & 23.8 \\
Unemployed & 61 & 76.3 \\
Monthly income & & \\
50\$-100\$ & 7 & 8.8 \\
100\$-200\$ & 51 & 63.8 \\
200\$-300\$ & 21 & 26.3 \\
\hline
\end{tabular}

\subsection{Previous History of Chronic Disease}

Table 2 the majority of the respondents who were tested form diabetics (97.5\%) never had diabetics before. Only $2 \%$ were diabetic. High blood pressure was high among the women tested with $77.5 \%$ of them had the history of hypertension. Only $22.5 \%$ were not affected with hypertension. Only $21.3 \%$ showed kidney disease while $78.8 \%$ had no previous records of kidney diseases. Majority of the women interviewed $76.3 \%$ had no family history of preeclampsia. Only $23.8 \%$ confirmed that they had family that they had family members with preeclampsia.

Table 2. Previous history of chronic disease.

\begin{tabular}{lll}
\hline Variables & $(\mathbf{n}=\mathbf{8 0})$ & $\mathbf{\%}$ \\
\hline knowledge on preeclampsia & & \\
Yes & 10 & 12.5 \\
No & 70 & 87.5 \\
History of diabetics & & \\
Yes & 2 & 2.5 \\
No & 78 & 97.5 \\
History of hypertension & & \\
Yes & 62 & 77.5 \\
No & 18 & 22.5 \\
History of kidney disease & & \\
Yes & 17 & 21.3 \\
No & 63 & 78.8 \\
History of Family preeclampsia & & \\
Yes & 19 & 23.8 \\
No & 61 & 76.3 \\
\hline
\end{tabular}

\subsection{Obstetric and Clinical Characteristics}

During their time of pregnancy, those who attended the antenatal care were almost the same $52.5 \%$ as those who never went to the hospital for the antenatal check up 47.5\%. Among the respondents, the age of first pregnancy was significant in the age bracket of $15-20$ with $55.0 \%$ followed by the age bracket of 25-30 years with $30.0 \%$. Between the age of 20-25 years had $13.8 \%$ and only $1.3 \%$ of the women who had their first pregnancy were above the age of $30.73 .8 \%$ of the respondents had family issues in their previous records and $26.3 \%$ of them appeared to have no signs of family problems or stress. The nutritional status of the respondents was very 
poor $66.3 \%$ followed by $28.8 \%$ fair and only $5 \%$ with good nutritional status.

Majority of the respondents used more salts during their pregnancy with $62.5 \%$ of them showed they used more salts and only $37.5 \%$ had not used more salts. History of preeclampsia was common among the respondents with $70 \%$ of them had the condition of preeclampsia before and only $30 \%$ of them were not tested with preeclampsia before. Among the pregnant women, those that were in the first trimester were almost the same as those that were at their third trimester with $42.5 \%$ and $38.8 \%$ respectively. Only $42.5 \%$ of the gestational age of pregnancy were at their first trimester.

Table 3. Obstetric and clinical characteristics.

\begin{tabular}{|c|c|c|}
\hline Variables & $(n=80)$ & $\%$ \\
\hline \multicolumn{3}{|l|}{ Have Proteinuria } \\
\hline Present & 47 & 58.8 \\
\hline Absent & 33 & 41.3 \\
\hline \multicolumn{3}{|c|}{ Attend antenatal care } \\
\hline Yes & 42 & 52.5 \\
\hline No & 38 & 47.5 \\
\hline \multicolumn{3}{|c|}{ Age of first pregnancy } \\
\hline $15-20$ year & 44 & 55.0 \\
\hline $20-25$ year & 11 & 13.8 \\
\hline 25-30 year & 24 & 30.0 \\
\hline Above 30 year & 1 & 1.3 \\
\hline \multicolumn{3}{|c|}{ History of family problem or stress } \\
\hline Yes & 59 & 73.8 \\
\hline No & 21 & 26.3 \\
\hline Total & 80 & 100.0 \\
\hline \multicolumn{3}{|l|}{ Nutritional status } \\
\hline Good & 4 & 5.0 \\
\hline Fair & 23 & 28.8 \\
\hline Poor & 53 & 66.3 \\
\hline \multicolumn{3}{|c|}{ Use more salts during pregnancy } \\
\hline Yes & 50 & 62.5 \\
\hline No & 30 & 37.5 \\
\hline \multicolumn{3}{|c|}{ Preeclampsia in previous pregnancy } \\
\hline Yes & 56 & 70.0 \\
\hline No & 24 & 30.0 \\
\hline Total & 80 & 100.0 \\
\hline \multicolumn{3}{|c|}{ Gestational age of pregnancy } \\
\hline First trimester & 34 & 42.5 \\
\hline Second trimester & 15 & 18.8 \\
\hline Third trimester & 31 & 38.8 \\
\hline
\end{tabular}

\section{Discussion}

The prevalence of preeclampsia among women in the world particularly in Africa differs. This is generally because women have different marital and pregnancy age, in Somalia, women who suffer from preeclampsia are mostly at the age of 30 and below compared to women in Kenya who suffer from preeclampsia are above the age of 30 this is because in Kenya, it is estimated that women don't get married early compared to Somalia [12, 13]. Its basic cause can also be traced to their marital status, for instance in Somalia the married women rate is much higher than in Kenya due to the high early marriage existence in Somalia than in Kenya. In similar cases, the educational level of women who suffer from preeclampsia in Somalia is unfortunately low compared to Uganda who have higher educational level of pregnant women with university degree and this is basically because there is great level of female education In Uganda than in Somalia thus making them to get high chances of employment and notable high monthly income rate than the women in Somalia. In terms of knowledge on preeclampsia, women in different parts in Africa vary, for example in Somalia due to limited educational level among pregnant women, they have insignificant knowledge about the effect of preeclampsia compared to the women in Ethiopia [16]. Gestational diabetics is condition in which the blood sugar level among pregnant women becomes high [17]. It affects some women in their first trimester but it differs in different countries as for Somalia, it is low compared to cases in Ethiopia, this is because in Somalia women eat organic food with less sugar compared to those in Ethiopia. Also, the use of organic food with less sugar and salt can reduce hypertension and thus cases and history of hypertension among pregnant women in Somalia is lower than in Ethiopia. The risk of preeclampsia is worse among women who have a history of preeclampsia. Women in Somalia have little knowledge of their family history in preeclampsia compared to the women in Uganda [18], this is because women in Somalia do not attend antenatal care frequently in order to get information about their history of preeclampsia. One aspect of the performance of a healthy pregnancy is the nutritional status of pregnant women in order to promote their health life style and prevent stress women are required to frequently be aware of their nutritional status [19], however much of the variance across countries appear to be attributable to cultural factors than to healthy nutritional status. For example, the use of more salts during pregnancy in Somalia is probably closely related to cultural practices than in Kenya.

\section{Strength and Weakness of This Study}

A key strength of this study is that a lot has been written about the prevalence of preeclampsia among pregnant women across the globe but very little or no records were there for the women suffering from preeclampsia in Somalia. This study shades light on how preeclampsia is one of the most common severe diseases among the pregnant women in Somalia and thus it will help researchers, doctors, medical students and other governmental health institutions to put focus and have a positive awareness on the prevalence of the disease. the other main strengths of this study is that when the information were collected, random method were used in order to prevent biasness for or against particular group of women either race or tribe. The main weakness of this report can be related to the fact that Somalia is country that is catching up from calamities such as internal wars and conflict hence the governmental health institutions data was not available. This resulted process of the accurate data collection to take a long time than the expected time. The title of this research is very wide and it requires a broad qualitative analysis across the country but due to in adequate funds and lack of time and also being the first research of this 
kind in Somalia, a small number of cases were focused on. That means it could not be expected to see the exact prevalence of preeclampsia among pregnant women in Somalia.

\section{Conclusion}

According to the study report, there are several factors leading to the prevalence o of preeclampsia among pregnant women in Somalia. Some of the main factors include maternal age, education, unemployed, family problem, and previous history of hypertension. Lack of education on matters related to the cause and how to prevent preeclampsia among women and the ignorance in the pregnancy nutrition and limited knowledge of health workers on certain maternal diseases specially preeclampsia are the main areas that need to be focused on. The need for: training of health workers, community sensitization on preeclampsia as well as proper supervision is noted and has to be addressed. Early marriage and bad cultural behavior such as FGM also need to be addressed as this factors may worsen the prevalence of preeclampsia among women. For the case of early marriage, if a small girl is diagnosed with preeclampsia it will be difficult for her to accept and seek medical attention fear of her husband to divorce her thus leading to psychological issues.

Based on the study the following recommendation were made: Regular training of health workers on preeclampsia causes, effects and how to prevent it from becoming a long lasting issue among pregnant women need to be addressed. Community sensitization and education specially women on the effect of preeclampsia and Proper supervision of already affected mothers also needs to be addressed

\section{Abbreviations}

ANC: Ante natal care

HDP: Hypertensive disorder of pregnancy

PIH: pregnancy induced hypertension

SPSS: statistical package for social science

WHO: world health organization

\section{Data Availability}

The data used to support the findings of this study are available from the corresponding author upon reasonable request.

\section{Ethical Consideration}

Ethics approval was obtained from the University of Somalia, college of Medicine and Health science. A formal permission letter was taken from the hospital management before the beginning of data collection.

\section{Conflict of Interest Statement}

The authors declare that they have no competing interests.

\section{Acknowledgements}

We want to express our heartfelt thanks to University of Somalia, College of Health and Medical Sciences. We also extend our thanks to hospital administrative for allowing us to collect data from patients, Authors were also greatly appreciated the study participants for their willingness to share their answers.

\section{References}

[1] Tessema GA, Tekeste A, Ayele TA. Preeclampsia and associated factors among pregnant women attending antenatal care in Dessie referral hospital, Northeast Ethiopia: A hospital-based study. BMC Pregnancy Childbirth. 2015; 15 (1).

[2] Otieno AN. Factors Contibuting To Adverse Outcomes Of Pre-Eclampsia Among Pregnant Women Attending Antenatal Clinics In Kibera Slums, Nairobi. 2012.

[3] Asia S, Asia S, Mediterranean E. Burden. Handb Dis Burdens Qual Life Meas. 2010; 4160-4160.

[4] Gele AA, Salad AM, Jimale LH, Kour P, Austveg B, Kumar B. Relying on Visiting Foreign Doctors for Fistula Repair: The Profile of Women Attending Fistula Repair Surgery in Somalia. Obstet Gynecol Int. 2017; 2017.

[5] Duhulo ZE. FACTORS ASSOCIATED WITH CHILDBIRTH COMPLICATIONS AMONG WOMEN OF REPRODUCTIVE AGE (15-49 YEARS) IN MOGADISHU, MASTER OF SCIENCE (Public Health) JOMO KENYATTA UNIVERSITY OF. ZAINAB ELMI DUHULO MASTER Sci (Public Heal JOMO KENYATTA Univ Agric Technol. 2016; 107.

[6] Verma MK, Kapoor P, Yadav R, Manohar RK. Risk Factor Assessment for Preeclampsia: A Case Control Study. Int J Med Public Heal. 2017; 7 (3): 172-7.

[7] Sammour MB, El-Kabarity H, Fawzy MM, Schindler a. E. Prevention and treatment of pre-eclampsia and eclampsia. Vol. 97, Journal of Steroid Biochemistry \& Molecular Biology. 2011. 439-440 p.

[8] Andarge RB, Anshebo AA, Halil HM, Kebede BA, Ahmed R. Prevalence and Associated Factors of Pre-eclampsia among Pregnant Women at Antenatal Booking in the Halaba Kullito General Hospital, Southern Ethiopia. Journal of Women' s Health Care. 2020; 1-9.

[9] Jeyabalan A. Epidemiology of preeclampsia: Impact of obesity. Nutr Rev. 2013; 71 (SUPPL1): 1-14.

[10] Berhe AK, Kassa GM, Fekadu GA, Muche AA. Prevalence of hypertensive disorders of pregnancy in Ethiopia: A systemic review and meta-analysis. BMC Pregnancy Childbirth. 2018; 18 (1): $1-11$.

[11] Un T. The UN in Somalia. 2014; 128. Available from: http://www.undp.org/content/dam/unct/somalia/docs/publicati ons/FINAL UN SOMALIA Yearbook Layout.pdf.

[12] United Nations Office for Coordination of Humanitarian Affairs. 2019 Humanitarian Needs Overview: Somalia. 2018; 38. Available from: https: //reliefweb.int/node/2936744. 
[13] Aden JA, Ahmed HJ, Östergren PO. Causes and contributing factors of maternal mortality in Bosaso District of Somalia. A retrospective study of 30 cases using a Verbal Autopsy approach. Glob Health Action [Internet]. 2019; 12 (1). Available from: https: //doi.org/10.1080/16549716.2019.1672314.

[14] Institute of Medicine (US) Committee on Improving Birth Outcomes. Reducing Maternal Mortality and Morbidity [Internet]. Improving Birth Outcomes: Meeting the Challenge in the Developing World. 2003. 372 p. Available from: http://www.ncbi.nlm.nih.gov/books/NBK222105/.

[15] Logan GG, Njoroge PK, Nyabola LO, Mweu MM. Determinants of preeclampsia and eclampsia among women delivering in county hospitals in Nairobi, Kenya. F1000Research. 2020; 9: 192.

[16] Agero G. PRE-ECLAMPSIA RISK FACTORS AMONG PREGNANT WOMEN ATTENDING IN FOUR PUBLIC HEALTH FACILITIES OF ADDIS ABABA CITY Administration, PRE-ECLAMPSIA RISK FACTORS
AMONG PREGNANT WOMEN ATTENDING IN. 2019; (March).

[17] Muche AA, Olayemi OO, Gete YK. Prevalence of gestational diabetes mellitus and associated factors among women attending antenatal care at Gondar town public health facilities, Northwest Ethiopia. BMC Pregnancy Childbirth. 2019; 19 (1): 334.

[18] Mayrink J, Souza RT, Feitosa FE, Rocha Filho EA, Leite DF, Vettorazzi J, et al. Incidence and risk factors for Preeclampsia in a cohort of healthy nulliparous pregnant women: a nested case-control study. Sci Rep. 2019; 9 (1): 1-9.

[19] Symington EA, Baumgartner J, Malan L, Zandberg L, Ricci C, Smuts CM. Nutrition during pregnancy and early development (NuPED) in urban South Africa: A study protocol for a prospective cohort. BMC Pregnancy Childbirth. 2018; 18 (1): $1-12$. 